\title{
Repercussões Econômicas dos Investimentos Gerados pelas Parcerias Público-Privadas em Minas Gerais
}

\author{
Economic Repercussions of Investments Generated by Public-Private Partnerships in \\ Minas Gerais
}

\author{
Weslem Rodrigues Fariaa \\ Matheus Alexandria Spositob \\ Admir Antonio Betarelli Juniorc
}

\begin{abstract}
Resumo: As parcerias público-privadas têm sido uma alternativa para ampliação e viabilização de investimentos em projetos de infraestrutura no Brasil desde 2004, quando houve sua regulamentação. $O$ artigo considera na análise a estrutura de absorção da Construção Civil e avalia os prováveis efeitos econômicos da implementação de PPP's em Minas Gerais até o ano de 2015, utilizando uma matriz inter-regional de insumo-produto. As projeções sinalizam um acréscimo de $\mathrm{R} \$ 11,90$ bilhões no PIB e de 351 mil postos de trabalho no Brasil. As PPP's indicam ainda para um aumento da receita tributária que representa cerca de $28 \%$ dos recursos dispendidos.
\end{abstract}

Palavras-chave: Parceria Público-Privado; Impactos Econômicos; Modelo Inter-Regional de Insumo-Produto.

Classificação JEL: L32; C67

\begin{abstract}
Public-private partnerships have been an alternative for expanding and making investments in infrastructure projects in Brazil possible since 2004, when they were regulated. The paper considers in the analysis the absorption structure of Civil Construction and assesses the probable economic effects of the implementation of PPPs in Minas Gerais until the year 2015, using an inter-regional input-product matrix. The projections indicate an increase of R \$ 11.90 billion in GDP and 351 thousand jobs in Brazil. PPP's also indicate an increase in tax revenue that represents about $28 \%$ of the resources spent.
\end{abstract}

Keywords: Private-Public Partnership. Economic Impact. Inter-Regional Input-Output Model.

\footnotetext{
${ }^{a}$ Professor da Faculdade de Economia e do Programa de Pós-Graduação em Economia (PPGE) da Universidade Federal de Juiz de Fora (UFJF). E-mail: weslem.faria@ufjf.edu.br.

${ }^{\mathrm{b}}$ Doutorando em Economia na FEA/USP. E-mail: matheus.alexandria@gmail.com.

${ }^{\mathrm{c}}$ Professor da Faculdade de Economia e do PPGE da UFJF. E-mail: admir.betarelli@ufjf.edu.br.
} 


\section{Introdução}

A Parceria Público-Privada (PPP) é uma forma de arranjo contratual que permite que o poder público una-se ao setor privado com o objetivo de garantir o financiamento, a construção, a renovação, a gestão ou a manutenção da prestação de um serviço. Esse arranjo contratual confere ao Estado a tarefa de reduzir alguns dos gargalos de infraestrutura na economia, bem como de minimizar os próprios custos públicos incorridos em projetos de investimentos. Além de aliviar o orçamento público, especialmente quando este apresenta fragilidade financeira, com essa nova forma de arranjo contratual há uma melhoria na qualidade dos serviços oferecidos pelos projetos de infraestrutura, pois o setor privado torna-se responsável por gerir tais projetos e passa a ser remunerado pela qualidade do serviço oferecido. Além disso, o Estado garante um fluxo contínuo de recursos, fazendo com que a iniciativa privada possa reduzir o risco e aumentar a carteira dos investimentos que dependem de perspectivas de longo prazo.

Em 30 de dezembro de 2004 foi elaborado o marco legal em âmbito nacional que regulamentaria as PPP's no Brasil, com a homologação da Lei Federal 11.079/2004. Não obstante, em dezembro de 2003, já havia uma legislação no estado de Minas Gerais, a Lei Estadual 14.868/2003. Essas leis constituem a normatização dos contratos de colaboração entre o Estado e o setor privado por meio dos quais, nos termos estabelecidos em cada caso, o ente privado participa da implantação e do desenvolvimento de obra, de serviço ou de empreendimento público, assim como da exploração e da gestão das atividades deles decorrentes, cabendo-lhe contribuir com recursos financeiros, materiais e humanos e sendo remunerado segundo o seu desempenho na execução das atividades contratadas (MINAS GERAIS, 2003; BRASIL, 2004). O sistema legal, a estabilidade macroeconômica, o controle da corrupção, a credibilidade e a transparência da autoridade pública são os principais preponderantes para a formação desses contratos (FERNANDEZ et al., 2015). Após a implementação das leis de regulamentação para as PPP's, o Brasil vem experimentando cada vez mais essas parcerias com a iniciativa privada, que modificam a forma como o investimento é realizado no país.

O estado de Minas Gerais possuía dez contratos de PPP's assinados e em execução, sendo o estado com maior número de PPP's assinadas até o ano de 2015. Dentre eles estão os projetos da MG-050, do Sistema Carcerário, UAI Fases I, II e III, do Aeroporto Regional da Zona da Mata, do Estádio Governador Magalhães Pinto, de coleta dos Resíduos Sólidos Urbanos para a Região Metropolitana de Belo Horizonte (RMBH) e o do Sistema Adutor Rio Manso (MINAS GERAIS, 2015).

Com o estado de Minas Gerais recebendo esses projetos, surgem vários questionamentos sobre os efeitos econômicos gerados pelas PPP's, sendo um deles o grau de intensidade e como se distribuíram os efeitos de uma expansão de demanda oriunda dos investimentos dos projetos com PPP's. A hipótese subjacente é de que a realização dos projetos pelas PPP's no estado de Minas Gerais deve provocar efeitos diretos e indiretos na economia do estado e no restante do país. Entende-se que esses investimentos programados podem gerar repercussões positivas sobre os principais indicadores 
macroeconômicos (e.g., produção e emprego nacional, importação, arrecadação tributária) e setoriais na economia de Minas Gerais, porém as intensidades e as distribuições desses efeitos dependem das interações setoriais dos principais fornecedores produtivos mais vinculados ao vetor de absorção de investimentos da construção civil no sistema produtivo mineiro.

Para atender esse mote de pesquisa, pode-se utilizar um modelo econômico capaz de realizar simulações de investimentos que levem em conta um sistema produtivo composto por setores interdependentes, intra e inter-regionais. O modelo baseado em matrizes de insumo-produto preenche esses requisitos metodológicos, pois permite a realização de choques de investimentos, levando em conta, ao mesmo tempo, as relações setoriais, dentro e entre as economias regionais. Assim, este artigo utiliza a matriz de insumo-produto inter-regional Minas Gerais - restante do Brasil disponibilizada pelo Núcleo de Economia Regional e Urbana da Universidade de São Paulo (Nereus). Foram calculados os efeitos multiplicadores da expansão de demanda acarretada pelos investimentos despendidos para a realização das PPP's, segundo os dados disponibilizados pela Secretaria de Estado e Desenvolvimento Econômico de Minas Gerais no ano de 2016.

O debate sobre os impactos e os efeitos das PPP's vem crescendo, e no Brasil o interesse tem aumentado após a criação do marco legal que instituiu normas gerais para licitação e contratação de PPP no âmbito dos Poderes da União, dos Estados, do Distrito Federal e dos municípios (BRASIL, 2004). De modo geral, esse debate ainda não foi consolidado e parte da discussão recai sobre os possíveis desdobramentos das PPP's. Outra questão sobre as PPP's é justamente sobre a possibilidade de que projetos sejam executados, ampliados ou continuados em situações de crise fiscal. Por exemplo, em fevereiro de 2016, o Governo de Minas Gerais anunciou um contingenciamento de R\$ 2 bilhões diante do cenário fiscal e financeiro não favorável enfrentado pela economia mineira (MINAS GERAIS, 2016). Tal medida veio em meio ao resultado negativo do PIB mineiro divulgado na época, de $-0,6 \%$ comparado ao quarto trimestre de 2015 (IBGE, 2016). Assim, a necessidade de restrição aos gastos públicos aliado a um cenário de queda no nível de atividade econômica aumenta a importância da procura de formas alternativas de incentivo ao investimento sem onerar ainda mais os gastos do Estado.

Portanto, além de oferecer uma análise quantitativa, este estudo pretende contribuir para o debate em curso sobre os efeitos econômicos das PPP's no estado de Minas Gerais, fundando-se na análise dos gastos despendidos em investimento pelo setor privado realizado pelas parcerias e de como esse investimento pode afetar os setores da economia. Por essa variante, espera-se que este artigo possa contribuir para a literatura ao projetar resultados que venham a ser úteis para avaliar os impactos das PPP's na economia, além de auxiliar os formadores de políticas públicas em suas tomadas de decisões.

O trabalho se organiza em cinco seções, incluindo esta introdução. A segunda seção descreve brevemente algumas das abordagens teóricas e empíricas sobre a temática do trabalho. A terceira seção aborda a metodologia de insumo-produto, as técnicas de simulação, as características da base de dados e a construção dos vetores de choque do 
modelo. A quarta analisa os resultados projetados, tanto sobre os principais indicadores macroeconômicos quanto sobre os setoriais. Por fim, a quinta seção apresenta as considerações finais, destacando as contribuições, os principais resultados, as limitações e as futuras extensões de pesquisa sobre as PPP's.

\section{Revisão de Literatura}

A adoção das PPP's no Brasil tem como finalidade aumentar o investimento no país, garantindo um serviço de qualidade sem que o Estado assuma toda a responsabilidade de financiar e gerir tais projetos. A parceria significa que a iniciativa privada entra com boa parte dos recursos necessários, além de gerenciar a prestação de serviços oferecidos para a população. Já o Estado, por seu turno, entra facilitando a obtenção de crédito para a iniciativa privada, além de garantir de forma contratual um fluxo estável de recursos ao longo do projeto, reduzindo assim os riscos de longo prazo assumidos pelo setor privado (MINAS GERAIS, 2015).

Países considerados em desenvolvimento, como o caso do Brasil, que sofrem com gargalos de infraestrutura e com baixo nível de investimento, poderiam estimular a criação de investimento induzido na tentativa de gerar desenvolvimento desequilibrado. No entanto, tal tarefa não é tão simples. Frischtak (2008) analisou os principais motivos que levam o Brasil a não conseguir aumentar a proporção do PIB que é destinado à Formação Bruta de Capital Fixo (FBCF) e romper com esses gargalos. Entre os principais fatores estão as restrições fiscais e a elevada rigidez orçamentária, que afetam diretamente os investimentos do setor público. Outro problema enfrentado pelo Estado é a limitação na capacidade de planejamento setorial e de execução, a ausência ou a fragilidade de marcos legais e regulatórios capazes de dar segurança jurídica e de assegurar a estabilidade e a transparência das regras da economia. Uma das tentativas do Estado de avançar no desenvolvimento econômico e garantir investimento foi utilizar dessa nova forma de arranjo contratual que são as PPP's.

O estudo de Brito e Silveira (2005) busca entender melhor esses contratos. Os autores chegaram à conclusão de que o governo utiliza desses contratos por dois motivos principais. O primeiro é garantir o investimento em determinados setores que o poder público julga importantes, podendo fazê-lo mesmo em contextos de restrições fiscais, visto que quem assume o papel de arcar com o investimento nesse modelo é o setor privado. O segundo é a busca pela maior eficiência na prestação de serviços públicos. Assim, os programas de parceria podem representar uma alternativa interessante para realizar empreendimentos de maneira eficiente. Já para a iniciativa privada, os contratos de PPP's são bastante atrativos, pois garantem um fluxo de recursos constante vindo do Estado, o que, para os autores, reduz drasticamente o risco incorporado aos investimentos de longo prazo, além de ter uma legislação apropriada. Na elaboração da lei brasileira foram incorporados elementos considerados em outros países como fatores críticos de sucesso. Dentre eles, destacam-se ao sistema legal existente, a preocupação com a disciplina fiscal e a adequada repartição de riscos entre os parceiros. $\mathrm{O}$ trabalho de 
Mesquita e Martins (2008) também traz informações sobre a implementação das PPP's no Brasil, mas direcionadas ao contexto do sistema de transporte.

A adoção de PPP's como forma de ampliar os investimentos ou mesmo de tornar possível a execução de grandes projetos para incremento da infraestrutura tem sido debatida em algumas frentes. Uma delas é sobre o desempenho das PPP's em termos de "sucesso". Hodge e Greve (2017) discutem profundamente as principais características envolvidas no conceito de PPP's para ajudar no entendimento do desempenho de projetos baseados nelas. Uma das principais hipóteses levantadas por esse estudo é de que o desempenho pode ser visto de forma subjetiva, uma vez que fatores que o determinam como positivo em uma PPP podem ser medidos pela força de regulação e de governança ao invés de serem medidos pelas características utilitaristas dos projetos. Dentre os fatores que delimitam as características políticas e de governança estão as dimensões de clareza, de processo jurídico, de transparência, de flexibilidade e de responsabilização (MOORE, 1995; FREIBERG, 2010). Outro fator levantado por Brinkerhoff e Brinkerhoff (2011) que pode ser considerado é o risco de corrupção, principalmente em países em desenvolvimento. Já para avaliar os custos de oportunidade financeiras das PPP's, análises contrafactuais podem ser aplicadas para verificar se os seus projetos seriam caros ou baratos em relação aos projetos exclusivamente públicos ou privados. Estudos para a Austrália (FITZGERALD, 2004), para o Canadá (VINING; BOARDMAN, 2008), para o Reino Unido (JUPE, 2009) e para a União Europeia (BLANC-BRUDE et al., 2009) foram realizados com essa finalidade.

Melville (2017) discute os principais desafios encontrados pelas economias em desenvolvimento na adoção de PPP's para alcançar objetivos econômicos. Tal trabalho indica que as instituições são determinantes para assegurar o desempenho positivo das PPP's. Além disso, conclui que os países em desenvolvimento devem estimular investimentos na forma de PPP's, principalmente com recursos domésticos. Roehrich et al. (2014) realizam uma extensa revisão de literatura sobre trabalhos realizados que tratam das PPP's. A principal conclusão desse estudo é a reduzida investigação empírica sobre elas.

Considerando trabalhos empíricos focados na economia brasileira, percebe-se uma quase inexistência de estudos que avaliaram efeitos econômicos de PPP's. A maioria dos trabalhos observados tiveram o objetivo de avaliar os efeitos de programas de investimento com vistas ao crescimento econômico, como o PAC (DOMINGUES et al., 2009), e de planejamento econômico (LEITE; PEREIRA, 2010). O trabalho de Vieira e Veríssimo (2009) tentou identificar os principais determinantes da taxa de crescimento econômico do Brasil e dos outros países do Brics, para isso utiliza a FBCF como proxy para o investimento em uma estimação de um modelo VAR; o único trabalho observado que buscou avaliar os efeitos das PPP's no Brasil foi o de Pereira e Ferreira (2008). No entanto, tal trabalho simulou os efeitos dos mecanismos associados à lei que a criou no Brasil. Não foram avaliados os efeitos de projetos vislumbrados. Portanto, percebe-se a existência de trabalhos que buscaram avaliar os efeitos sistêmicos sobre a economia dos investimentos de PPP's. 
O presente trabalho diferencia-se também de outros encontrados na literatura, que utilizam modelos de insumo-produto ao realizar projeções considerando alternativas para a construção do vetor do investimento dos gastos privados das PPP's (e.g. FUNDAÇÃO JOÃO PINHEIRO, 2010; DOMINGUES; CARVALHO, 2012; CARDOSO et al., 2014). Foram criados dois vetores de choque. Um com base na Unidade Padrão Setorial de Investimento (UPSI) da Construção Civil mediante as estimativas das Matrizes de Absorção de Investimentos (MAI) de Miguez et al. (2014). E outro fundamentado na tradicional Unidade padrão de Investimento (UPI), definida pela composição setorial do vetor de investimento (FBCF), disponível na matriz inter-regional (MGxRB) de 2008.

\section{Metodologia}

\subsection{Modelo Insumo-Produto}

Para simular os prováveis efeitos econômicos da realização dos projetos de PPP's no estado de Minas Gerais foi utilizado um modelo de insumo-produto. Tal metodologia tem a vantagem de isolar os efeitos sistêmicos de equilíbrio geral de uma política ou fenômeno de interesse sobre indicadores como produção, emprego, valor agregado e importações (GUILHOTO, 2001; HADDAD, 2004). O sistema produtivo responde a choques monetários com base em variações nos componentes da demanda final que exógenos. $\mathrm{Na}$ versão tradicional do modelo de insumo-produto tais componentes não variam devido a mudanças da produção. São cinco os usuários finais: consumo das famílias, consumo do governo, exportações, investimentos (formação bruta de capital fixo) e variação de estoques. Além disso, o modelo pressupõe preços rígidos, oferta perfeitamente elástica e tecnologia de retornos constantes de escala (Leontief) (MILLER; BLAIR, 2009; BETARELLI et al., 2015).

$\mathrm{O}$ estudo utilizou a matriz de insumo-produto inter-regional disponibilizada pelo Núcleo de Economia Regional e Urbana da Universidade São Paulo (Nereus). ${ }^{1}$ Tal matriz foi construída com base nos dados das Contas Nacionais e das Contas Regionais segundo a metodologia apresentada por Guilhoto et al. (2010), Guilhoto e Sesso Filho (2010) e Guilhoto e Sesso Filho (2005). A matriz subdivide as atividades econômicas em 26 setores. A base de dados representa a estrutura produtiva da economia brasileira em 2008, com os fluxos de comércio de bens e serviços entre o estado de Minas Gerais e o restante do Brasil.

Em sua versão inter-regional simples, o modelo de insumo-produto pode ser representado matematicamente, em notação matricial, como:

$$
\mathbf{X}=\mathbf{A X}+\mathbf{F}
$$

\footnotetext{
${ }^{1}$ http://www.usp.br/nereus/?fontes=dados-matrizes. Acesso em: 21 jul. 2016.
} 
em que $\mathbf{X}=\left[\begin{array}{l}X^{r} \\ X^{s}\end{array}\right]$ é o vetor de produção de cada setor $j$ nas regiões $r$ e $s ; \mathbf{A}=\left[\begin{array}{ll}A^{r r} & A^{r s} \\ A^{s r} & A^{r r}\end{array}\right]$ é a matriz de coeficientes técnicos do setor j pelo insumo i dos fluxos intra $\left(a_{i j}^{r r}\right.$ e $\left.a_{i j}^{S S}\right) \mathrm{e}$ inter-regionais $\left(a_{i j}^{r s}\right.$ e $\left.a_{i j}^{s r}\right) ; \mathbf{A X}=\mathbf{Z}$, ou seja, representa a matriz de consumo intermediário, cujos elementos são monetários; e $\mathbf{F}=\left[\begin{array}{c}f_{i f}^{r} \\ f_{i f}^{s}\end{array}\right]$ é a matriz de demanda final do produto $i$ e o usuário final $f$ em cada região. Resolvendo a equação (1), tem-se:

$$
\mathbf{X}=\mathbf{B F}
$$

sendo I a matriz identidade; $X$ a produção total necessária para atender a demanda final $\mathrm{F}$; e $(\mathbf{I}-\mathbf{A})^{-\mathbf{1}}=\mathbf{B}$, que corresponde aos requisitos diretos e indiretos pelo insumo $\mathrm{i}$ do setor j por variação de uma unidade monetária de demanda final. A matriz B é conhecida como a matriz inversa de Leontief. Assim, com (2), é possível projetar os efeitos potenciais sobre a produção $(\Delta \mathbf{X})$ em virtude dos choques de investimentos decorrentes das PPP's $\left(\Delta \mathbf{f}_{I N V}\right)$, ou melhor:

$$
\Delta \mathbf{X}=\mathbf{B} \Delta \mathbf{f}_{\mathbf{I} N V}
$$

É possível ainda decompor os efeitos entre diretos $\left(\Delta \mathbf{X}^{\text {Direto }}\right)$ e indiretos $\left(\Delta \mathbf{X}^{\text {Indireto }}\right)$ conforme a seguinte expressão:

sendo que $\Delta \mathbf{X}^{\text {Direto }}=\mathbf{A} \Delta \mathbf{f}_{I N V}$.

$$
\Delta \mathbf{X}^{\text {Indireto }}=\Delta \mathbf{X}-\Delta \mathbf{X}^{\text {Direto }}
$$

É assumida uma relação fixa $\left(\mathbf{C}_{k}\right)$ com a produção de cada setor para calcular os efeitos sobre os outros principais indicadores, como o emprego $(\Delta \mathbf{E})$ e a importação $(\Delta \mathbf{M})$, como se segue:

$$
\Delta \mathbf{K}=\mathbf{C}_{k} \Delta \mathbf{X}
$$

tal que $\Delta \mathbf{K}=[\Delta \mathbf{E}, \Delta \mathbf{M}]$ é a variação de um indicador específico com a sua respectiva matriz diagonal de coeficientes estruturais $\left(\mathbf{C}_{k}\right)$. Para projetar o impacto sobre os impostos indiretos $(\Delta \mathbf{T})$, deve-se considerar a expansão tanto da produção doméstica $(\Delta \mathbf{X})$ quanto da importação $(\Delta \mathbf{M})$. Isso se deve ao fato de que conceitualmente os impostos indiretos como ICMS, IPI, Outros Impostos menos Subsídios incidem conjuntamente sobre os fluxos de vendas de bens domésticos e importados. Assumindo que as importações possuem uma relação fixa com o nível de produção, então:

$$
\Delta \mathbf{T}=\mathbf{C}_{T}(\Delta \mathbf{X}+\Delta \mathbf{M})+\Delta \mathbf{D}=\mathbf{C}_{T}\left(\mathbf{B} \Delta \mathbf{f}_{I N V}\right)+\mathbf{C}_{T}\left(\mathbf{C}_{M} \mathbf{B} \Delta \mathbf{f}_{I N V}\right)+\left(\mathbf{C}_{D} \mathbf{B} \Delta \mathbf{f}_{I N V}\right)
$$

sendo $\mathbf{C}_{T}, \mathbf{C}_{M}$, e $\mathbf{C}_{D}$ as matrizes diagonais de coeficientes estruturais dos impostos indiretos (ICMS , IPI, outros impostos menos subsídios), da importação e dos impostos sobre a importação, respectivamente. O último termo da equação (6), que trata exclusivamente dos impostos sobre importação $\left(\mathbf{C}_{D} \mathbf{B} \Delta \mathbf{f}_{I N V}\right)$, foi incluído em virtude da disponibilidade dessa informação na matriz de insumo-produto. Essa separação permite tornar os resultados projetados um pouco mais precisos, pois tradicionalmente se aplica o vetor total dos impostos indiretos, sem qualquer tratamento diferenciado por tipos de impostos (e.g., FUNDAÇÃO JOÃO PINHEIRO, 2010). Apesar disso, esse aperfeiçoamento leva a uma pequena diferença se comparado ao método tradicional. 
Como na equação (4), os efeitos totais, diretos e indiretos podem ser calculados similarmente para os demais indicadores econômicos, porém considerando os seus correspondentes coeficientes estruturais. Desse modo, por conveniência e para não tornar a descrição das técnicas exaustiva, optou-se por ocultar essa decomposição em cada indicador subsequente.

Para projetar os impactos dos desembolsos sobre o PIB, pela ótica da renda, devese considerar a variação do valor adicionado mais a variação dos impostos indiretos, tal como:

$$
\Delta P I B=\sum_{i=1}^{I}(\Delta \mathbf{V}+\Delta \mathbf{T})
$$

tal que $\Delta \mathbf{V}=\mathbf{C}_{V} \mathbf{B} \Delta \mathbf{f}_{I N V}$ representa uma matriz de efeitos projetados sobre o valor adicionado a preços básicos dos setores produtivos, de maneira que $\mathbf{C}_{V}$ é a sua correspondente matriz diagonal de coeficientes estruturais.

\subsection{Vetores de Choques}

Os vetores de choque foram formulados com os dados disponibilizados pela Secretaria de Estado e Desenvolvimento Econômico de Minas Gerais. Como os projetos foram realizados em períodos diferentes, utilizou-se o Índice Nacional de Preços ao Consumidor Amplo (IPCA) para computar todos os recursos em investimento da iniciativa privada para o ano base, tornando-os compatíveis com a matriz de insumoproduto de 2008. Os dez projetos realizados em Minas Gerais se distribuíram em seis áreas: Rodoviário, Segurança, Esportes e Lazer, Atendimento ao Cidadão, Saneamento Básico e Aéreo (Tabelas 1, 2 e 3). Os projetos da MG-050, Complexo do Mineirão e Ampliação do Sistema Rio Manso foram aqueles com os maiores montantes de investimento entre as PPP's, representando 71,49\% de todo o montante. As Tabelas 1, 2 e 3 reportam o detalhamento dos gastos em cada projeto e uma breve descrição de cada um deles. Os vetores de choques foram gerados com base nos montantes totais de investimento de todos os projetos supracitados.

Em geral, as análises de insumo-produto são feitas com choques de demanda em determinados setores, a fim de se avaliar os efeitos sobre o sistema produtivo. Ao analisar os impactos dos investimentos das PPP's por parte do ente privado, considera-se que essa aplicação gera um efeito desencadeador na economia. Destarte, a escolha do vetor de choque desempenha importante papel nas projeções econômicas. Como os projetos representam etapas de construção envolvendo, em grande medida, criação e ampliação de infraestrutura e de centros de atendimento, o valor total da carteira de investimento das Tabela 1, 2 e 3 será distribuído conforme a estrutura de alocação dos investimentos da Construção Civil. É preciso, com isso, definir a forma de distribuição dos dispêndios dos projetos das PPP's de investimentos no setor de Construção Civil, pois tais recursos não representam choques de demanda na própria atividade produtiva, mas naquelas que compõem o vetor de absorção da Construção Civil. 
Tabela 1: Dispêndio e Descrição dos 10 Projetos Realizados até 2015 das PPP's no Estado de Minas Gerais (em valores de 2008) - Parte 1

\begin{tabular}{|c|c|c|c|c|}
\hline Cód. & Área & Projetos & $\begin{array}{c}\text { Custos do } \\
\text { Investimento } \\
\text { Privado em R\$ } \\
\text { milhões } \\
\end{array}$ & Descrição do Projetos \\
\hline A1 & Rodoviário & MG-050 & $7.010,32$ & $\begin{array}{l}\text { O projeto de PPP da MG-050 compreende a } \\
\text { exploração da Rodovia MG-050, no trecho } \\
\text { entroncamento BR-262 (Juatuba) - Itaúna - } \\
\text { Divinópolis - Formiga - Piumhi - Passos - } \\
\text { São Sebastião do Paraíso, no trecho Entro } \\
\text { MG 050/Entro BR-265 da BR } 49115 \text { do km } \\
0,0 \text { ao km } 4,65 \text { e no trecho São Sebastião do } \\
\text { Paraíso - Divisa MG/SP da Rodovia BR } 265 .\end{array}$ \\
\hline A2 & Segurança & $\begin{array}{l}\text { Complexo } \\
\text { Penitenciário } \\
\text { de Ribeirão } \\
\text { das Neves }\end{array}$ & $1.617,63$ & $\begin{array}{l}\text { O projeto prevê a disponibilização de mais de } \\
3000 \text { vagas, em cinco unidades prisionais, } \\
\text { sendo três para o regime fechado e duas para } \\
\text { o regime semiaberto. Além disso, é previsto } \\
\text { a construção de uma unidade de } \\
\text { administração central do Complexo Penal. }\end{array}$ \\
\hline A3 & $\begin{array}{l}\text { Esportes e } \\
\text { Lazer }\end{array}$ & $\begin{array}{l}\text { Complexo } \\
\text { do Mineirão }\end{array}$ & $5.924,96$ & $\begin{array}{l}\text { Exploração mediante concessão } \\
\text { administrativa, da operação e da manutenção, } \\
\text { precedidas de obras de reforma, renovação e } \\
\text { adequação do complexo do Mineirão. }\end{array}$ \\
\hline A4 & $\begin{array}{l}\text { Atendimento ao } \\
\text { Cidadão }\end{array}$ & $\begin{array}{l}\text { UAI fase } 1 \\
\text { (6 Unidades) }\end{array}$ & 82,63 & $\begin{array}{l}\text { Implantação, gestão, operação e manutenção } \\
\text { de } 6 \text { Unidades de Atendimento Integrado. }\end{array}$ \\
\hline
\end{tabular}

Fonte: Elaboração própria com base nos dados disponibilizados pela Secretaria de Estado e Desenvolvimento Econômico de Minas Gerais.

Podem ser utilizadas duas estratégias para fazer a distribuição dos investimentos das PPP's. A primeira é utilizando a Unidade Padrão de Investimento (UPI) tradicional, em que os recursos são distribuídos com base na composição (participações) de cada setor na FBCF, após dedução da parcela dos impostos indiretos e das importações. Tal estratégia foi utilizada por Domingues e Carvalho (2012) para analisar os impactos econômicos dos desembolsos do Banco de Desenvolvimento de Minas Gerais.

A outra estratégia é utilizar a Unidade Padrão Setorial de Investimento (UPSI), que se baseia em matrizes de absorção de investimentos. Essas matrizes permitem a identificação do comportamento específico de alocação dos investimentos para cada setor. Dessa maneira, é possível definir de forma específica como a Construção Civil aloca os recursos de investimentos entre os fornecedores produtivos. As matrizes de absorção utilizadas foram aquelas estimadas por Miguez et al. (2014) para o ano de 2008. A vantagem da UPSI sobre a UPI reside especialmente em considerar o comportamento individualizado de cada setor ao invés do comportamento "médio" da economia.

As matrizes regionais divulgadas pela Fundação João Pinheiro fornecem a estrutura do vetor de FBCF intra e inter-regionalmente, permitindo somente a elaboração da Unidade Padrão de Investimento para Minas Gerais. A UPI é comumente utilizada como referência para qualquer setor econômico quando se desconhece o comportamento 
setorial de alocação dos recursos de investimentos. Dessa maneira, a hipótese subjacente da UPI é a de que qualquer atividade setorial apresentaria a mesma forma de alocação dos investimentos em Minas Gerais. Não obstante, setores econômicos utilizam diferentes insumos intermediários para formar uma unidade adicional de capital. Cada setor apresenta, pois, uma Unidade Padrão Setorial de Investimento. Essas duas formas carregam limitação e hipótese: a) UPI generaliza a alocação de investimento setorial conforme o padrão da economia regional ou nacional; b) UPSI discrimina a alocação de investimento setorialmente, porém reproduz o padrão nacional para a economia mineira. Essa pesquisa fez a opção pela UPSI por avaliar que a limitação é relativamente menor e que há mais vantagem que a UPI.

\section{Tabela 2: Dispêndio e Descrição dos 10 Projetos Realizados até 2015 das PPP's no Estado de Minas Gerais (em valores de 2008) - Parte 2}

\begin{tabular}{|c|c|c|c|c|}
\hline Cód. & Área & Projetos & $\begin{array}{l}\text { Custos do Investimento } \\
\text { Privado em R\$ milhões }\end{array}$ & Descrição do Projetos \\
\hline A5 & $\begin{array}{l}\text { Saneamento } \\
\text { Básico }\end{array}$ & $\begin{array}{l}\text { Resíduos } \\
\text { Sólidos } \\
\text { Urbanos (43 } \\
\text { municípios } \\
\text { da RMBH) }\end{array}$ & $2.654,55$ & $\begin{array}{l}\text { A Região Metropolitana de Belo } \\
\text { Horizonte (RMBH) será a primeira do } \\
\text { Brasil a garantir a correta destinação de } \\
100 \% \text { dos resíduos sólidos urbanos, } \\
\text { com a proposta de Parceria Público- } \\
\text { Privada (PPP) para exploração, } \\
\text { mediante concessão administrativa, } \\
\text { dos serviços de transbordo, tratamento } \\
\text { e disposição final de resíduos sólidos } \\
\text { urbanos produzido na região. O modelo } \\
\text { envolve incentivos para geração de } \\
\text { energia com o resíduo e para a redução } \\
\text { do volume de resíduos aterrados } \\
\text { atendendo a } 43 \text { municípios. }\end{array}$ \\
\hline A6 & $\begin{array}{l}\text { Atendimento } \\
\text { ao Cidadão }\end{array}$ & $\begin{array}{c}\text { UAI fase } 2 \\
\quad(23 \\
\text { Unidades })\end{array}$ & 334,83 & $\begin{array}{l}\text { O projeto envolve a implantação, o } \\
\text { gerenciamento, a operação e a } \\
\text { manutenção de } 23 \text { UAI's do Estado de } \\
\begin{array}{l}\text { Minas Gerais, atendendo a } 21 \\
\text { municípios. }\end{array}\end{array}$ \\
\hline A7 & $\begin{array}{l}\text { Atendimento } \\
\text { ao Cidadão }\end{array}$ & $\begin{array}{c}\text { UAI Fase } 3 \\
\text { (UAI Praça } \\
\text { Sete) }\end{array}$ & 28,13 & $\begin{array}{l}\text { O projeto envolve a implantação, o } \\
\text { gerenciamento, a operação e a } \\
\text { manutenção da Unidade de } \\
\text { Atendimento Integrado da Praça Sete } \\
\text { de Setembro no Município de Belo } \\
\text { Horizonte. }\end{array}$ \\
\hline
\end{tabular}

Fonte: Elaboração própria com base nos dados disponibilizados pela Secretaria de Estado e Desenvolvimento Econômico de Minas Gerais.

Uma etapa adicional foi aplicada para compatibilizar as matrizes de absorção dimensionadas em 110 produtos e em 55 setores para um sistema com os 26 setores da matriz inter-regional. Como suposição dessa tarefa de construção do vetor de choque, 
considerou-se a mesma estrutura de alocação setorial das matrizes de absorção do investimento nacional para Minas Gerais.

Tabela 3: Dispêndio e Descrição dos 10 Projetos Realizados até 2015 das PPP's no Estado de Minas Gerais (em valores de 2008) - Parte 3

\begin{tabular}{|c|c|c|c|c|}
\hline Cód. & Área & Projetos & $\begin{array}{l}\text { Custos do Investimento } \\
\text { Privado em R\$ milhões }\end{array}$ & Descrição do Projetos \\
\hline A8 & Aéreo & $\begin{array}{c}\text { Aeroporto } \\
\text { Regional da } \\
\text { Zona da Mata }\end{array}$ & 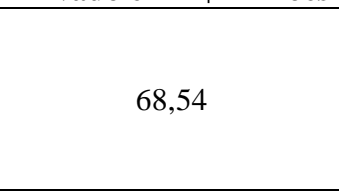 & $\begin{array}{l}\text { O modelo de concessão envolve a } \\
\text { realização de investimentos privados } \\
\text { no ARZM, alicerçados em contrato que } \\
\text { compartilha os riscos de demanda entre } \\
\text { o setor privado e público. }\end{array}$ \\
\hline A9 & $\begin{array}{l}\text { Saneamento } \\
\text { Básico }\end{array}$ & $\begin{array}{c}\text { Ampliação do } \\
\text { Sistema Rio } \\
\text { Manso }\end{array}$ & $3.593,35$ & $\begin{array}{l}\text { O projeto prevê a ampliação da oferta } \\
\text { de água potável na RMBH dos atuais } \\
362,8 \text { milhões de litros/dia para } 501,12 \\
\text { milhões de litros/dia. O volume } \\
\text { adicional será capaz de atender um } \\
\text { incremento de demanda equivalente a } \\
\text { uma população da ordem de } 635 \text { mil } \\
\text { pessoas/dia. }\end{array}$ \\
\hline A10 & $\begin{array}{c}\text { Saneamento } \\
\text { Básico }\end{array}$ & $\begin{array}{l}\text { Sistema de } \\
\text { Esgotamento } \\
\text { Sanitário de } \\
\text { Divinópolis }\end{array}$ & $1.806,72$ & $\begin{array}{l}\text { Esse projeto de concessão } \\
\text { administrativa prevê a ampliação e } \\
\text { operação parcial do sistema de } \\
\text { esgotamento sanitário do município de } \\
\text { Divinópolis pelo prazo de } 26 \text { anos. }\end{array}$ \\
\hline Total & & & $23.121,65$ & \\
\hline
\end{tabular}

Fonte: Elaboração própria com base nos dados disponibilizados pela Secretaria de Estado e Desenvolvimento Econômico de Minas Gerais.

Os vetores de choque foram elaborados, portanto, com base nos $\mathrm{R} \$ 23,121$ bilhões em valores de 2008 despendidos pelo setor privado na construção dos projetos das PPP's. As Tabelas 4-7 fornecem as formas de alocação do investimento, utilizando a UPI e a UPSI do setor de Construção Civil, bem como as diferenças entre elas. A coluna referente à UPI foi obtida após cálculo da estrutura do vetor de FBCF de Minas Gerais existente na matriz inter-regional Minas Gerais x restante do Brasil. A coluna referente à UPSI foi obtida utilizando a estrutura das matrizes de absorção mencionadas anteriormente. Foi considerada que a estrutura da FBCF de Minas Gerais é a mesma da nacional, existente nas matrizes de absorção. De acordo com ela, 65,55\% da FBCF do setor de Construção Civil nacional era proveniente da oferta nacional a preços básicos; $13,79 \%$ era proveniente da oferta importada e 20,66\% era proveniente de impostos indiretos. Para desagregar a parte da FBCF proveniente da oferta nacional entre Minas Gerais e restante do Brasil, utilizou-se a informação fornecida pela matriz inter-regional. Segundo tal matriz, a participação do restante do Brasil na FBCF de Minas Gerais era de 22,32\%. Assim, aplicou-se o percentual de $43,23 \%(65,55 \%$ - 22,32\%) sobre a estrutura da participação da FBCF proveniente da oferta nacional para obter a parte de Minas Gerais e o percentual de $22,23 \%$ sobre a mesma estrutura para obter a parte do restante do Brasil. 
Isso permitiu a manutenção da consistência com as matrizes de absorção, já que as participações das importações e dos impostos na FBCF do setor de Construção Civil foram preservadas.

As Tabelas 4-7 fornecem a estrutura setorial de distribuição dos recursos das PPP's que será utilizada como vetor de choque para as simulações no modelo. As projeções irão considerar a estrutura da UPSI. Como salientado anteriormente, do total de recursos das PPP's, isto é, R\$ 23.121,65 milhões, 65,55\% (ou R\$ 15.156,53 milhões) representam choques diretos na demanda dos fornecedores da Construção Civil, ou seja, são destinados para a compra de insumos domésticos produzidos pelos setores mais vinculados à FBCF que compõem o vetor de absorção de investimentos da Construção Civil. A parcela restante dos recursos representa os gastos com a compra de insumos importados $(13,79 \%$ ou $\mathrm{R} \$ 3.187,40$ milhões) e com pagamentos de impostos indiretos (20,66\% ou $\mathrm{R} \$ 4.777,72$ milhões).

Tabela 4: Vetores de Choque e Comparação entre UPI e UPSI - MG (continua)

\begin{tabular}{c|l|c|c|c|c|c}
\hline \hline \multirow{2}{*}{ Cód. } & \multicolumn{1}{|c|}{ Descrição } & \multicolumn{3}{c|}{ Participação (\%) } & \multicolumn{2}{c}{ Investimento (R\$ milhões) } \\
\cline { 3 - 7 } & & UPI & UPSI & Diferença & UPI & UPSI \\
\hline S1 & $\begin{array}{l}\text { Agricultura, silvicultura, } \\
\text { exploração florestal }\end{array}$ & 0,68 & 0,00 & $-0,68$ & 156,63 & 0,08 \\
\hline S2 & Pecuária e pesca & 1,39 & 0,00 & $-1,39$ & 321,40 & 0,00 \\
\hline S3 & Mineração & 0,00 & 0,00 & 0,00 & 0,87 & 0,58 \\
\hline S4 & Alimentos, bebidas e fumo & 0,02 & 0,03 & 0,01 & 3,81 & 7,20 \\
\hline S5 & Têxtil, vestuário e calçados & 0,01 & 0,01 & 0,01 & 1,36 & 3,39 \\
\hline S6 & Madeira, papel e impressão & 0,05 & 0,13 & 0,08 & 12,32 & 31,21 \\
\hline S7 & Refino de petróleo, coque e álcool & 0,01 & 0,04 & 0,03 & 2,98 & 9,73 \\
\hline S8 & $\begin{array}{l}\text { Outros produtos químicos e } \\
\text { farmacêuticos }\end{array}$ & 0,03 & 0,10 & 0,08 & 6,23 & 23,78 \\
\hline S9 & Artigos de borracha e plástico & 0,01 & 0,05 & 0,04 & 3,21 & 12,54 \\
\hline S10 & $\begin{array}{l}\text { Cimento e outros produtos de } \\
\text { minerais não-metálicos }\end{array}$ & 0,01 & 0,03 & 0,02 & 2,36 & 6,35 \\
\hline S11 & Metalurgia & 2,10 & 7,22 & 5,12 & 485,49 & $1.670,28$ \\
\hline S12 & Máquinas e equipamentos & 3,21 & 20,78 & 17,56 & 742,84 & $4.803,62$ \\
\hline S13 & Material elétrico e eletrônicos & 2,67 & 3,57 & 0,90 & 618,21 & 826,05 \\
\hline \hline
\end{tabular}

Fonte: Resultados da pesquisa. 
Tabela 5: Vetores de Choque e Comparação entre UPI e UPSI - MG (continuação)

\begin{tabular}{c|l|c|c|c|c|c}
\hline \multirow{2}{*}{ Cód. } & \multicolumn{1}{|c|}{ Descrição } & \multicolumn{3}{c|}{ Participação (\%) } & \multicolumn{2}{c}{ Investimento (R\$ milhões) } \\
\cline { 3 - 7 } & & UPI & UPSI & Diferença & UPI & UPSI \\
\hline S14 & Material de transporte & 8,15 & 0,77 & $-7,37$ & $1.883,90$ & 178,95 \\
\hline S15 & Indústrias diversas & 0,71 & 0,86 & 0,15 & 164,67 & 199,23 \\
\hline S16 & $\begin{array}{l}\text { Eletricidade e gás, água, esgoto e } \\
\text { limpeza urbana }\end{array}$ & 0,00 & 0,00 & 0,00 & 1,12 & 0,33 \\
\hline S17 & Construção & 31,06 & 3,36 & $-27,70$ & $7.182,55$ & 777,40 \\
\hline S18 & Comércio & 6,98 & 4,66 & $-2,32$ & $1.614,64$ & $1.078,56$ \\
\hline S19 & $\begin{array}{l}\text { Transporte, armazenagem e } \\
\text { correio }\end{array}$ & 1,02 & 0,81 & $-0,21$ & 236,14 & 186,60 \\
\hline S20 & Serviços privados & 0,63 & 0,48 & $-0,15$ & 145,18 & 110,00 \\
\hline S21 & $\begin{array}{l}\text { Intermediação financeira e } \\
\text { seguros }\end{array}$ & 0,01 & 0,00 & 0,00 & 1,42 & 0,42 \\
\hline S22 & Serviços imobiliários e aluguel & 0,76 & 0,22 & $-0,54$ & 175,49 & 49,84 \\
\hline S23 & $\begin{array}{l}\text { Serviços de alojamento e } \\
\text { alimentação }\end{array}$ & 0,01 & 0,01 & 0,00 & 2,17 & 1,31 \\
\hline S24 & Educação mercantil e pública & 0,03 & 0,01 & $-0,02$ & 6,67 & 2,07 \\
\hline S25 & Saúde mercantil e pública & 0,07 & 0,03 & $-0,04$ & 16,42 & 7,30 \\
\hline S26 & $\begin{array}{l}\text { Administração pública e } \\
\text { seguridade social }\end{array}$ & 0,05 & 0,04 & $-0,02$ & 12,70 & 8,86 \\
\hline \hline
\end{tabular}

Fonte: Resultados da pesquisa.

Tabela 6: Vetores de Choque e Comparação entre UPI e UPSI - Restante do Brasil (continua)

\begin{tabular}{c|l|c|c|c|c|c}
\hline \multirow{2}{*}{ Cód. } & \multicolumn{1}{|c|}{ Descrição } & \multicolumn{3}{c|}{ Participação (\%) } & \multicolumn{2}{c}{ Investimento (R\$ milhões) } \\
\cline { 3 - 7 } & & UPI & UPSI & Diferença & UPI & UPSI \\
\hline \multirow{2}{*}{ S1 } & Agricultura, silvicultura, \\
& exploração florestal & 0,23 & 0,00 & $-0,23$ & 53,97 & 0,04 \\
\hline S2 & Pecuária e pesca & 0,70 & 0,00 & $-0,70$ & 162,94 & 0,00 \\
\hline S3 & Mineração & 0,00 & 0,00 & 0,00 & 0,29 & 0,30 \\
\hline S4 & Alimentos, bebidas e fumo & 0,01 & 0,02 & 0,00 & 3,00 & 3,72 \\
\hline S5 & Têxtil, vestuário e calçados & 0,01 & 0,01 & 0,00 & 1,50 & 1,75 \\
\hline S6 & Madeira, papel e impressão & 0,09 & 0,07 & $-0,02$ & 21,74 & 16,11 \\
\hline S7 & Refino de petróleo, coque e álcool & 0,02 & 0,02 & 0,00 & 4,06 & 5,02 \\
\hline S8 & $\begin{array}{l}\text { Outros produtos químicos e } \\
\text { farmacêuticos }\end{array}$ & 0,04 & 0,05 & 0,02 & 8,46 & 12,28 \\
\hline S9 & Artigos de borracha e plástico & 0,02 & 0,03 & 0,00 & 5,35 & 6,47 \\
\hline S10 & $\begin{array}{l}\text { Cimento e outros produtos de } \\
\text { minerais não-metálicos }\end{array}$ & 0,01 & 0,01 & 0,00 & 2,55 & 3,28 \\
\hline S11 & Metalurgia & 0,89 & 3,73 & $\underline{2,84}$ & 206,20 & 862,38 \\
\hline S12 & Máquinas e equipamentos & 8,44 & 10,73 & $\underline{2,28}$ & $1.952,19$ & $2.480,15$ \\
\hline S13 & Material elétrico e eletrônicos & 4,86 & 1,84 & $\underline{-3,01}$ & $1.123,48$ & 426,50 \\
\hline \hline
\end{tabular}

Fonte: Resultados da pesquisa. 
Tabela 7: Vetores de Choque e Comparação entre UPI e UPSI - Restante do Brasil (continuação) e Demais Componentes

\begin{tabular}{c|l|c|c|c|c|c}
\hline \multirow{2}{*}{ Cód. } & \multirow{2}{*}{ Descrição } & \multicolumn{3}{c|}{ Participação $(\%)$} & \multicolumn{2}{c}{$\begin{array}{c}\text { Investimento (R\$ } \\
\text { milhões) }\end{array}$} \\
\cline { 3 - 7 } & & UPI & UPSI & Diferença & UPI & UPSI \\
\hline S14 & Material de transporte & 1,05 & 0,40 & $-0,65$ & 243,53 & 92,39 \\
\hline S15 & Indústrias diversas & 0,45 & 0,44 & 0,00 & 103,42 & 102,87 \\
\hline S16 & $\begin{array}{l}\text { Eletricidade e gás, água, esgoto e } \\
\text { limpeza urbana }\end{array}$ & 0,00 & 0,00 & 0,00 & 0,24 & 0,17 \\
\hline S17 & Construção & 2,64 & 1,74 & $-0,90$ & 610,47 & 401,38 \\
\hline S18 & Comércio & 2,12 & 2,41 & 0,29 & 489,12 & 556,87 \\
\hline S19 & $\begin{array}{l}\text { Transporte, armazenagem e } \\
\text { correio }\end{array}$ & 0,34 & 0,42 & 0,08 & 78,69 & 96,34 \\
\hline S20 & Serviços privados & 0,19 & 0,25 & 0,06 & 43,64 & 56,79 \\
\hline S21 & $\begin{array}{l}\text { Intermediação financeira e } \\
\text { seguros }\end{array}$ & 0,00 & 0,00 & 0,00 & 0,30 & 0,21 \\
\hline S22 & Serviços imobiliários e aluguel & 0,15 & 0,11 & $-0,04$ & 35,75 & 25,73 \\
\hline S23 & $\begin{array}{l}\text { Serviços de alojamento e } \\
\text { alimentação }\end{array}$ & 0,00 & 0,00 & 0,00 & 0,62 & 0,68 \\
\hline S24 & Educação mercantil e pública & 0,01 & 0,00 & 0,00 & 1,44 & 1,07 \\
\hline S25 & Saúde mercantil e pública & 0,02 & 0,02 & 0,00 & 4,06 & 3,77 \\
\hline S26 & $\begin{array}{l}\text { Administração pública e } \\
\text { seguridade social }\end{array}$ & 0,02 & 0,02 & 0,00 & 3,84 & 4,57 \\
\hline & $\begin{array}{l}\text { Demanda dos fornecedores } \\
\text { produtivos }\end{array}$ & 82,01 & 65,55 & $-16,46$ & $18.961,63$ & $15.156,53$ \\
\hline & Importação & 10,63 & 13,79 & 3,16 & $2.457,03$ & $3.187,40$ \\
\hline & Impostos indiretos totais & 7,37 & 20,66 & $\underline{13,30}$ & $1.702,99$ & $4.777,72$ \\
\hline & Total geral & 100,00 & 100,00 & 0,00 & $23.121,65$ & $23.121,65$ \\
\hline \hline
\end{tabular}

Fonte: Resultados da pesquisa.

\section{Resultados e Discussões}

\subsection{Projeções sobre Indicadores Macroeconômicos}

Esta seção analisa os prováveis efeitos sobre indicadores macroeconômicos selecionados de forma discriminada para Minas Gerais e restante do Brasil, devido aos investimentos das PPP's realizados no referido estado. O Gráfico 1 apresenta as projeções econômicas em variações percentuais e a Tabela 8 reporta as mesmas informações em termos monetários. Os recursos investidos pelas PPP's para a construção e para a ampliação da infraestrutura e de pontos de centros de atendimento relacionados à cadeia produtiva da Construção Civil ( $\mathrm{R} \$ 15,16$ bilhões) promoveriam um crescimento de $0,46 \%$ no Produto Interno Bruto (PIB) do Brasil, atingindo um adicional de quase R\$ 11,90 bilhões (Tabela 8). O estado de Minas Gerais contribuiria com 53,51\% desse 
aumento da atividade econômica no país. Tal parcela é menor do que a observada no total de variação de demanda dos fornecedores domésticos para a FBCF na Construção Civil das Tabelas 4-7 entre as regiões, pois 65,95\% seriam destinados para os setores de Minas Gerais. O PIB do restante do Brasil seria influenciado mais que proporcionalmente com o estímulo aos setores produtivos de Minas Gerais e da própria região. Isso indica forte interdependência na cadeia produtiva entre as duas regiões.

\section{Gráfico 1: Efeitos Sobre os Principais Indicadores Macroeconômicos (var. \%)}

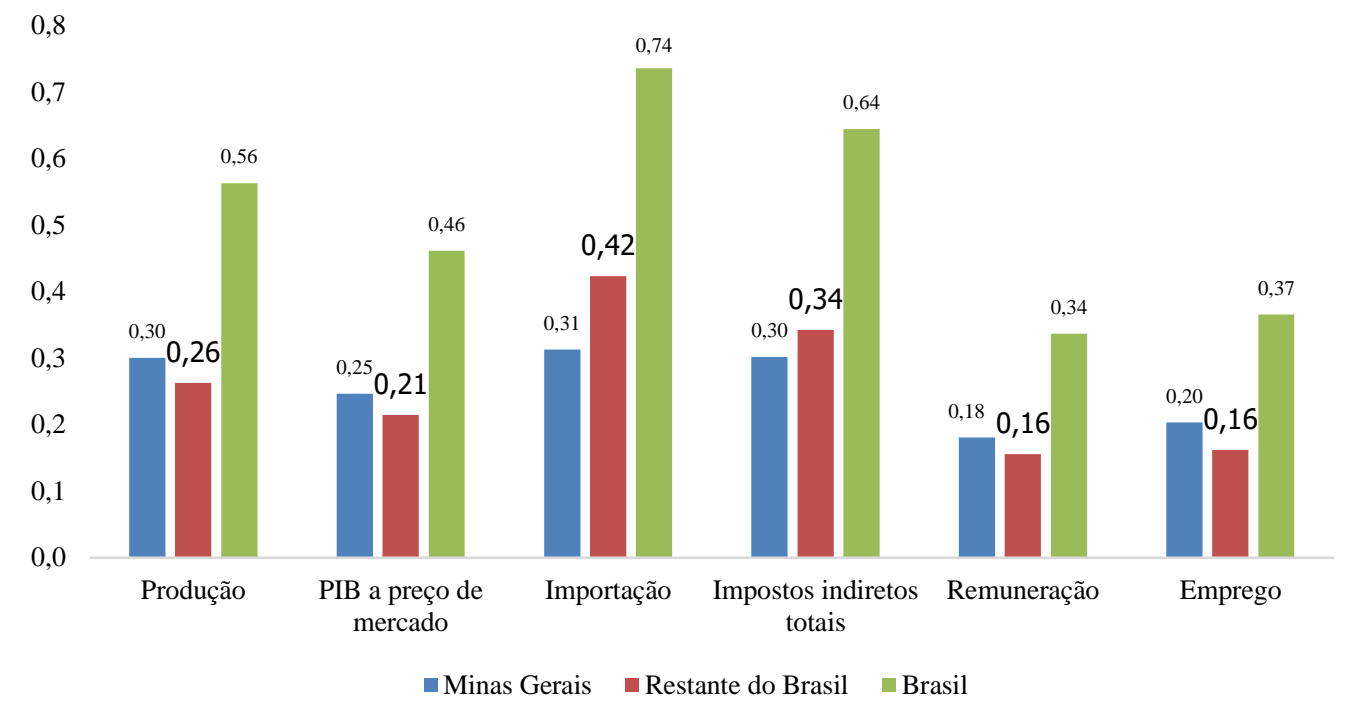

Fonte: Resultados da pesquisa.

Similarmente, os recursos das PPP's impulsionariam a produção nacional em R\$ 29,89 bilhões, uma variação de $0,56 \%$. Do efeito total, $53,32 \%$ seria sobre a economia mineira e 46,68\% sobre o restante do Brasil, novamente demonstrando grandes vazamentos inter-regionais. Os recursos de investimentos provocariam aumento na demanda por insumos intermediários, estimulando a produção das atividades ligadas ao fornecimento desses insumos. Isso geraria novo aumento de demanda das atividades setoriais produtoras e assim por diante. Os efeitos totais da expansão da demanda final são transmitidos para todo o sistema inter-regional. Em suma, a intensidade e a transmissão desses efeitos dependerão da própria magnitude da expansão da demanda final, dos setores inicialmente mais afetados e dos canais de encadeamento existentes entre os setores e as regiões. Dessa maneira, de um total de $\mathrm{R} \$ 15,16$ bilhões em recursos para investimentos, a produção nacional teria um efeito multiplicador em 1,97 vezes ao correspondente valor investido. Não foram encontrados na literatura aplicada resultados dos efeitos de PPP's sobre a economia brasileira para fins de comparação. 
O cômputo da repercussão sobre o emprego é similar ao da produção, com a ponderação dos respectivos coeficientes estruturais. Ou melhor, a variação positiva na produção nacional implica em variação positiva também no emprego. Tal resultado é intuitivo, já que choques de investimentos tendem a aumentar a demanda por trabalho das atividades produtivas de forma a atender à expansão da produção. A soma dos efeitos diretos e indiretos na geração de emprego é retrata no Gráfico 1 e na Tabela 8. A aplicação de recursos na forma de investimentos das PPP's geraria um efeito positivo de $0,37 \%$ no emprego agregado. Em termos de ocupações, tal variação representaria um adicional total de 351.866 postos de trabalho formais e informais no Brasil. Desse total, 195.823 empregos seriam gerados em Minas Gerais ou 55,65\% e 156.043 no restante do Brasil ou $44,35 \%$. Observa-se também grande transbordamento inter-regional na geração de empregos.

Tabela 8: Efeitos Sobre os Principais Indicadores Macroeconômicos (R\$ bilhões)

\begin{tabular}{l|c|c|c}
\hline \hline Indicadores Macroeconômicos & Minas Gerais & Restante do Brasil & Brasil \\
\hline Produção & 15,94 & 13,95 & 29,89 \\
\hline PIB a preço de mercado & 6,37 & 5,53 & 11,90 \\
\hline Importação & 0,81 & 1,09 & 1,90 \\
\hline Impostos indiretos totais & 0,66 & 0,74 & 1,40 \\
\hline Remuneração & 2,29 & 1,98 & 4,27 \\
\hline Emprego ${ }^{1}$ & 195,82 & 156,04 & 351,87 \\
\hline \hline
\end{tabular}

Como os investimentos das PPP's absorvidos pela Construção Civil demandam insumos não apenas dos setores produtivos de Minas Gerais, mas também de setores do restante do Brasil, tem-se que o estímulo à geração de emprego tende a ser compatível com aquele sobre a produção. Ou seja, se existe grande transbordamento inter-regional dos efeitos sobre a produção das atividades produtivas, o mesmo tende a ocorrer com relação ao emprego. Os efeitos sobre a remuneração tende a acompanhar o resultado da produção e do emprego. Tais efeitos também são computados considerando coeficientes de remuneração. A intuição sobre a variação positiva da remuneração é que o maior nível de atividade produtiva devido ao estímulo do choque de demanda geralmente aumenta a demanda por trabalho e, consequentemente, da remuneração associada a tal fator.

O estímulo à atividade econômica, devido aos recursos investidos com as PPP's, repercutiu positivamente sobre as importações. $\mathrm{O}$ aumento da produção nacional implica na expansão da demanda tanto por insumos domésticos quanto por insumos importados. Com isso, as importações brasileiras cresceriam $0,74 \%$ ou $\mathrm{R} \$ 1,90$ bilhões. Esse valor representa 59,66\% de toda a demanda por importações da Construção Civil em 2008. As importações de Minas Gerais expandiriam $0,31 \%$ ou $\mathrm{R} \$ 0,81$ bilhões e as importações do restante do Brasil, $0,42 \%$ ou $\mathrm{R} \$ 1,09$ bilhões. O aumento das importações do restante do Brasil seria maior em relação à variação de Minas Gerais, uma vez que se assumiu a mesma estrutura de demanda por importações da matriz inter-regional para Minas Gerais 
e restante do Brasil. Nessa matriz, Minas Gerais representa 6,69\% das importações de insumos dos setores produtivos. Mesmo assim, devido ao aumento mais intenso do nível de atividade de Minas Gerais, as importações dessa região apresentaram tal expansão. Considerando essa participação (6,69\%), dos recursos de investimentos das PPP's destinados às importações, $\mathrm{R}$ \$ 213,36 milhões (ou R \$ 0,21 bilhões) seriam a parcela correspondente à Minas Gerais do total de R\$3.187,40 milhões (Tabela 7). Desse modo, os efeitos sobre as importações de Minas Gerais seriam 3,79 vezes maior do que o valor inicial. $^{2}$

Vale ressaltar que os modelos de insumo-produtos não consideram efeitos competitivos. Assim, a possibilidade de substituição entre os insumos das diferentes fontes, doméstica e importada, está ausente. O efeito sobre as importações é consequência da expansão da demanda das atividades produtivas que aumentaram a produção em virtude do choque exógeno de investimento e dos coeficientes estruturais da matriz de insumo-produto. Outras hipóteses subjacentes aos modelos de insumo-produto como linearidade do sistema de equações, de retornos constante de escala, de oferta infinita de insumos e de ausência de preços relativos condicionam parte dos resultados projetados.

Os prováveis impactos dos investimentos das PPP's sobre a produção doméstica e a demanda por importados aumentariam a arrecadação de impostos indiretos totais (ICMS, IPI e outros impostos menos subsídios) do Brasil em 0,64\% ou R \$ 1,40 bilhões. Desse percentual, 0,30\% (R \$ 0,66 bilhões) seria a parcela de contribuição de Minas Gerais e 0,34\% do restante do Brasil ( $\mathrm{R} \$ 0,74$ bilhões). Assim como no caso das importações, utilizou-se a estrutura da matriz inter-regional para desagregar a parcela dos impostos indiretos deduzidos da matriz de absorção da FBCF da Construção Civil referente à Minas Gerais e ao restante do Brasil. Tal estrutura indica que 7,86\% dos impostos indiretos eram associados ao estado de Minas Gerais. Em termos de valores dos investimentos das PPP's gastos apenas com impostos indiretos (R \$ 4.777,72 milhões), tal percentual representa $\mathrm{R} \$ 375,57$ milhões de impostos indiretos gastos de Minas Gerais. O valor restante, $\mathrm{R} \$ 4.402,16$ milhões, seriam os valores com impostos indiretos totais gastos do restante do Brasil apenas com a aplicação dos recursos das PPP's. Considerando os impostos indiretos totais gerados por Minas Gerais, ter-se-ia um efeito 1,75 vezes maior em relação aos impostos indiretos totais arrecadados diretamente com os investimentos das PPP's (Gráfico 1 e Tabelas 7 e 8). ${ }^{3}$

Embora a desagregação dos impostos indiretos totais pela estrutura da matriz interregional indique uma parcela pequena para Minas Gerais, os impostos indiretos totais gerados são quase duas vezes maior em relação aos impostos indiretos totais absorvidos em virtude do aumento do nível de atividade setorial dessa região. Além disso, para o total de $\mathrm{R} \$ 1,40$ bilhões de acréscimo de impostos indiretos totais, 49,84\% seria devido aos impostos indiretos totais gerados por Minas Gerais (Tabela 8).

\footnotetext{
${ }^{2}$ Razão entre $\mathrm{R} \$ 808,47$ milhões e $\mathrm{R} \$ 213,36$ milhões.

${ }^{3}$ Razão entre R\$ 655,60 milhões e R \$ 375,57 milhões.
} 
As relações envolvendo os impostos absorvidos diretamente com a utilização dos recursos de investimentos das PPP's, bem como os impostos gerados devido à ampliação da atividade econômica decorrente do aumento da demanda e da produção da economia estão sintetizadas na Tabela 9, que fornece um esquema mais detalhado sobre os efeitos da aplicação dos investimento das PPP's sobre a ótica de arrecadação. A discussão é que, independentemente dos vazamentos inter-regionais criados, a arrecadação de impostos se dá em um ambiente de implementação de recursos privados, reduzindo os custos de oportunidade inerentes à execução dos investimentos pelo setor público. A vantagem das PPP's é criar possibilidades de criação de infraestrutura mesmo em cenários de contenção de gastos públicos, de crises fiscais e de ambiente de recessão econômica. Não obstante, a aplicação dos recursos ainda gera efeitos econômicos positivos, além de aumentar a própria receita tributária.

Tabela 9: Esquema da Arrecadação com as PPP's (R\$ milhões)

\begin{tabular}{l|c|c|c}
\hline \hline Indicadores & Minas Gerais & Restante do Brasil & Total \\
\hline Recursos das PPP's (A) & $10.584,61$ & $12.537,05$ & $23.121,65$ \\
\hline Total de impostos (B) & $1.219,62$ & $5.292,69$ & $6.512,31$ \\
\hline Impostos indiretos (B.1) & $1.031,17$ & $5.146,06$ & $6.177,22$ \\
\hline Gerados & 655,60 & 743,90 & $1.399,50$ \\
\hline Dispêndio direto (vetores de choque) & 375,57 & $4.402,16$ & $4.777,72$ \\
\hline Impostos sobre produção (B.2) & 188,45 & 146,64 & 335,09 \\
\hline Gerados & 144,84 & 124,12 & 268,96 \\
\hline Dispêndio direto & 43,61 & 22,51 & 66,12 \\
\hline (B) / (A) & $11,52 \%$ & $42,22 \%$ & $28,17 \%$ \\
\hline
\end{tabular}

Fonte: Resultados da pesquisa.

Os valores de dispêndio direto com impostos indiretos totais, isto é, os impostos indiretos totais arrecadados diretamente com a execução direta das PPP's (R \$ 4.777,72 milhões) representam 20,66\% dos investimentos ( $\mathrm{R} \$ 23.121,65$ milhões). O esquema de arrecadação também inclui os dispêndios diretos e gerados sobre a produção. Os impostos sobre a produção seguem a estrutura da FBCF da Construção Civil associada à matriz de absorção setorial. Portanto, tem-se que todos os impostos arrecadados (devido ao dispêndio direto) ou gerados representariam 28,17\% do total dos investimentos das PPP's (Tabela 9). ${ }^{4}$

Os valores apresentados na Tabela 9 permitem que outras associações sejam realizadas. Do total dos investimentos das PPP's, tem-se que $45,58 \%$ seriam empreendidos em Minas Gerais. No entanto, dos recursos aplicados sobre a demanda por insumos dos setores produtivos $(65,55 \%$ ou $\mathrm{R} \$ 15.156,53$ milhões), $65,95 \%$ ou $\mathrm{R} \$$ 9.995,68 milhões seriam sobre os setores de Minas Gerais. Tal parcela dos recursos é que possui maior capacidade de gerar efeitos de encadeamento sobre a economia. Os valores

\footnotetext{
${ }^{4}$ Os valores apresentados na Tabela 9 permitem que outras associações sejam realizadas.
} 
do restante do Brasil no total dos recursos foram mais altos justamente devido à forma de distribuição dos impostos indiretos totais e das importações. No entanto, esses valores não influenciam os efeitos gerados. Observando os valores para o Brasil, a importância sobre a arrecadação direta e sobre a arrecadação gerada permanece inalterada.

\subsection{Projeções Setoriais}

Os resultados das projeções setoriais são retratados nas Tabelas 10 e 11, que apresentam os dez principais setores em termos de variação na produção tanto em Minas Gerais quanto no restante do Brasil. Em termos de aumento na produção, a atividade do setor de Máquinas e equipamentos cresceria $66,17 \%$ em Minas Gerais, atingindo um acréscimo do valor bruto da produção (VBP) de $\mathrm{R} \$ 4,97$ bilhões. Isto se deve ao fato de esse setor ser o principal fornecedor de insumos domésticos no vetor de absorção dos investimentos da Construção Civil. Ou melhor, tal setor tinha uma participação na UPSI de 48,06\% em ambas as regiões. Lembrando que tal relação é observada nacionalmente de acordo com a matriz de absorção do Brasil e admitida ser a mesma para Minas Gerais.

Tabela 10: Principais Projeções Setoriais (Produção e Emprego) - Minas Gerais

\begin{tabular}{|c|c|c|c|c|c|c|c|}
\hline \multirow[b]{2}{*}{ Setores } & \multicolumn{2}{|c|}{ VBP } & \multirow{2}{*}{$\begin{array}{c}\text { Posi- } \\
\text { çãoo }\end{array}$} & \multirow{2}{*}{$\begin{array}{c}\text { Ocupa- } \\
\text { ções } \\
\text { (milha- } \\
\text { res) }\end{array}$} & \multirow[b]{2}{*}{$\mathrm{C}_{\mathrm{E}}{ }^{1}$} & \multirow{2}{*}{$\begin{array}{c}\text { Posi- } \\
\text { ção }\end{array}$} & \multirow{2}{*}{$\begin{array}{c}\text { Efeito } \\
\text { Indireto } \\
\text { (Part. \%) }\end{array}$} \\
\hline & $\begin{array}{l}\text { R\$ } \\
\text { bi. }\end{array}$ & $\underset{\%}{\text { Var. }}$ & & & & & \\
\hline Máquinas e equipamentos & 4,97 & 66,17 & 1 & 33 & 6,67 & 2 & 96,84 \\
\hline Metalurgia & 3,51 & 6,91 & 2 & 11 & 3,13 & 6 & 58,18 \\
\hline Comércio & 1,64 & 4,06 & 3 & 60 & 36,87 & 1 & 75,80 \\
\hline Material elétrico e eletrônicos & 1,08 & 14,35 & 4 & 7 & 6,17 & 7 & 79,96 \\
\hline Construção & 0,81 & 3,37 & 5 & 25 & 30,48 & 4 & 97,22 \\
\hline Serviços privados & 0,72 & 1,54 & 6 & 30 & 41,47 & 3 & 56,36 \\
\hline Transporte, armazenagem e correio & 0,65 & 2,71 & 7 & 11 & 17,55 & 5 & 56,48 \\
\hline Material de transporte & 0,39 & 1,27 & 8 & 1 & 2,52 & 12 & 62,25 \\
\hline Intermediação financeira e seguros & 0,35 & 2,03 & 9 & 1 & 3,76 & 10 & 36,97 \\
\hline $\begin{array}{l}\text { Eletricidade e gás, água, esgoto e } \\
\text { limpeza urbana }\end{array}$ & 0,34 & 1,95 & 10 & 1 & 2,64 & 14 & 53,09 \\
\hline
\end{tabular}

Fonte: Resultados da pesquisa.

${ }^{1}$ CE: Coeficiente de emprego, ocupações por um milhão de VBP.

Os investimentos em infraestrutura e em ampliação de centros de atendimento acionam os fornecedores da Construção Civil, uma vez que estes necessitam de máquinas como tratores, guindastes, britadeiras, equipamentos para a fabricação e a colocação de asfalto, para a terraplanagem, entre outros. Vale destacar que o setor de Máquinas e equipamentos ainda possui grande interdependência com as outras atividades mais associadas à $\mathrm{FBCF}$, como Metalurgia, Cimento e outros produtos de minerais nãometálicos e Material elétrico e eletrônicos, apresentando, com isso, grande parcela de efeitos indiretos $(96,84 \%)$. O coeficiente estrutural de emprego do setor de Máquinas e 
equipamentos tem um valor de quase 7 ocupações para cada um milhão adicional de VBP. Assim, mesmo com o forte crescimento na produção, tal característica estrutural indica o adicional de 33 milhares postos de trabalho na economia, obtendo a segunda posição no ranking de geração de ocupações. Com relação ao restante do Brasil, observa-se comportamento similar para o setor, que foi também o mais impactado em termos de produção (acréscimo de 2,53\% ou $\mathrm{R} \$ 2,69$ bilhões) e apresentou grande proporção de efeitos indiretos $(95,35 \%)$, mas obteve a terceira posição no ranking de geração de ocupações.

Tabela 11: Principais Projeções Setoriais (Produção e Emprego) - Restante do Brasil

\begin{tabular}{|c|c|c|c|c|c|c|c|}
\hline \multirow{2}{*}{ Setores } & \multicolumn{2}{|c|}{ VBP } & \multirow{2}{*}{$\begin{array}{c}\text { Posi- } \\
\text { ção }\end{array}$} & \multirow{2}{*}{$\begin{array}{l}\text { Ocupa- } \\
\text { ções } \\
\text { (milha- } \\
\text { res) }\end{array}$} & \multirow{2}{*}{$\mathrm{CE}^{1}$} & \multirow{2}{*}{$\begin{array}{c}\text { Posi- } \\
\text { çãoo }\end{array}$} & \multirow{2}{*}{$\begin{array}{c}\text { Efeito } \\
\text { Indireto } \\
\text { (Part. \%) }\end{array}$} \\
\hline & $\mathbf{R} \$ \mathbf{b i}$ & $\begin{array}{l}\text { Var. } \\
\%\end{array}$ & & & & & \\
\hline Máquinas e equipamentos & 2,69 & 2,53 & 1 & 15 & 5,39 & 3 & 95,35 \\
\hline Metalurgia & 2,51 & 1,52 & 2 & 14 & 5,55 & 4 & 58,91 \\
\hline Comércio & 1,19 & 0,29 & 3 & 40 & 33,73 & 1 & 74,65 \\
\hline Serviços privados & 0,85 & 0,16 & 4 & 29 & 34,22 & 2 & 72,86 \\
\hline Material elétrico e eletrônicos & 0,82 & 0,74 & 5 & 4 & 4,43 & 8 & 68,88 \\
\hline Transporte, armazenagem e correio & 0,79 & 0,33 & 6 & 13 & 16,24 & 5 & 64,30 \\
\hline Intermediação financeira e seguros & 0,76 & 0,29 & 7 & 3 & 3,39 & 11 & 53,15 \\
\hline $\begin{array}{l}\text { Outros produtos químicos e } \\
\text { farmacêuticos }\end{array}$ & 0,73 & 0,37 & 8 & 2 & 2,35 & 15 & 64,74 \\
\hline Refino de petróleo, coque e álcool & 0,57 & 0,34 & 9 & 1 & 0,95 & 22 & 70,15 \\
\hline Mineração & 0,53 & 0,36 & 10 & 1 & 1,66 & 18 & 85,91 \\
\hline
\end{tabular}

Fonte: Resultados da pesquisa.

${ }^{1}$ CE: Coeficiente de emprego, ocupações por um milhão de VBP.

Percebe-se que os setores com maior acréscimo na produção não são necessariamente aqueles com maior variação no emprego. Por exemplo, o Refino de petróleo, coque e álcool seria o oitavo com maior impacto na produção do restante do Brasil, mas apenas o vigésimo segundo em termos de geração de emprego. A diferença entre os impactos sobre a produção e sobre o emprego deve-se justamente à ponderação dos choques pelos coeficientes estruturais de emprego. Como pode ser observado para o setor Refino de petróleo, coque e álcool, tal coeficiente é igual a 0,95, o que significa que há menos de um emprego para cada um milhão de VBP no setor (Tabelas 10 e 11). 


\section{Gráfico 2: Efeitos Regionais Sobre o VBP Setorial (Part. \%)}

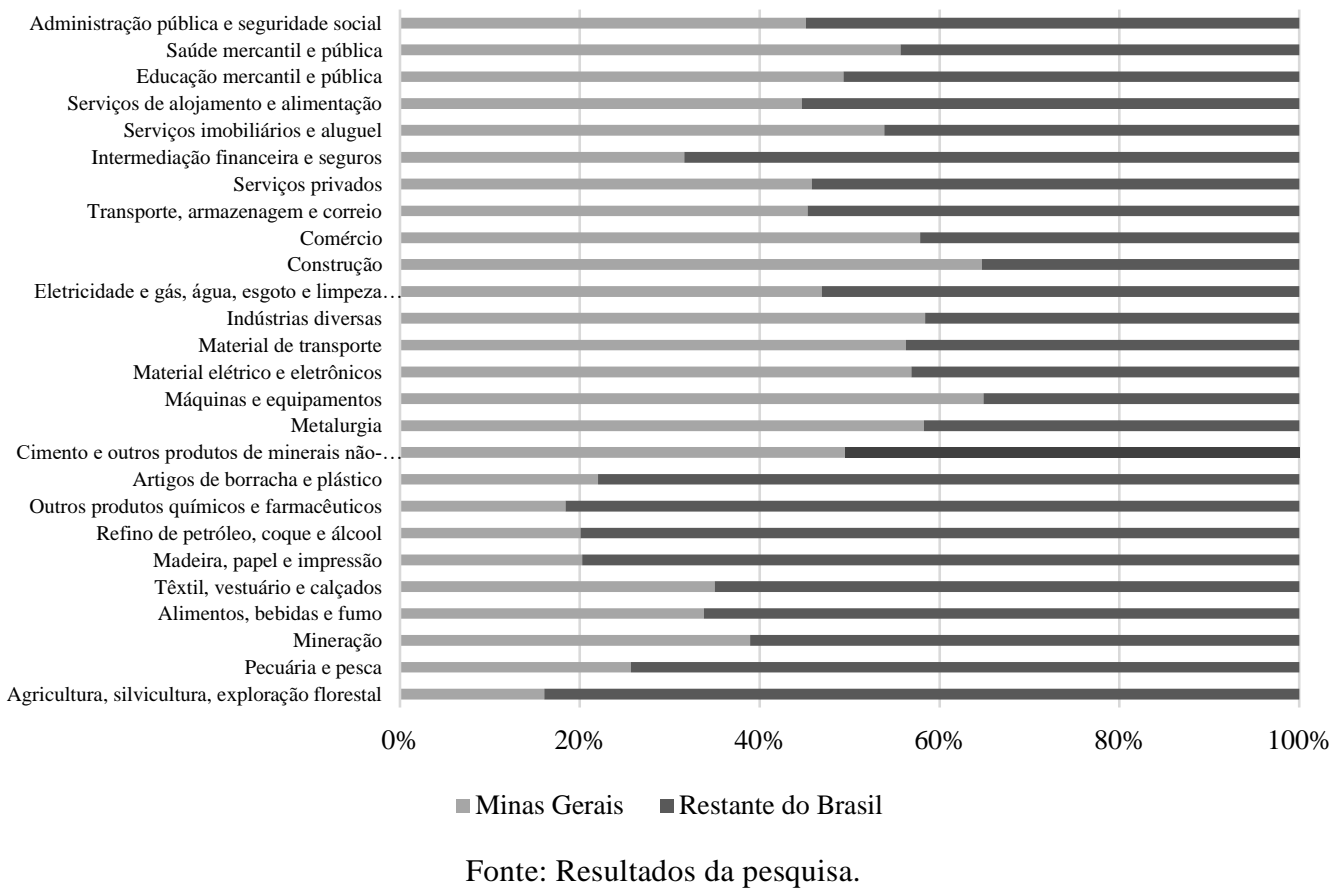

As Tabelas 10 e 11 indicam que os três primeiros setores mais impactados em termos de VBP são os mesmos em Minas Gerais e no restante do Brasil. A partir do quarto, tem-se uma mudança na composição e no ranking dos setores. O Gráfico 2 retrata a participação de cada região no acréscimo do VBP de cada setor. Como os investimentos das PPP's em Minas Gerais são absorvidos pelos fornecedores da Construção Civil tanto desse estado quanto do restante do Brasil, tem-se um efeito conjunto da repartição dos recursos entre as regiões e os setores e também de transbordamentos criados devido a interdependência inter-regional e setorial. Os setores que notoriamente tem maior participação de Minas Gerais na variação do VBP são Máquinas e equipamentos, Construção e outros da cadeia industrial. Tais atividades setoriais têm em comum o fato de que possuem suas demandas mais localmente. $\mathrm{O}$ resultado também demonstra uma capacidade de Minas Gerais em atender às demandas setoriais, principalmente com relação aos referidos setores. A participação do restante do Brasil na produção adicional do país é maior principalmente nos setores menos influenciados diretamente com os investimentos das PPP's, dada a estrutura do vetor de absorção da Construção Civil. Entre tais setores pode-se citar Agricultura, silvicultura e exploração florestal; Madeira, papel e impressão e Refino de petróleo, coque e álcool. 


\section{Conclusão}

O objetivo deste trabalho foi projetar os prováveis desdobramentos econômicos dos investimentos realizados pela iniciativa privada nas PPP's em Minas Gerais, bem como avaliar sua distribuição entre os setores da economia mineira e do restante do Brasil. Os efeitos oriundos dessas inversões nas construções de obras em alguns setores da economia de Minas Gerais foram analisados sobre os principais indicadores macroeconômicos e setoriais, entre os quais se encontram PIB, produção, emprego, remuneração, impostos e importações. Para tal, utilizou-se uma matriz de insumoproduto inter-regional configurada entre o estado de Minas Gerais e o restante do Brasil, no ano de 2008, estruturada em 26 setores econômicos. Para a análise de política, adotouse os valores de investimentos disponibilizados pela Secretaria de Estado e Desenvolvimento Econômico de Minas Gerais. De posse desses dados de desembolsos e da matriz insumo-produto de 2008, construiu-se um vetor de choque utilizando a metodologia da UPSI do setor de Construção Civil.

A UPSI do setor de Construção Civil, criada com base nas MAI, considera informações sobre a absorção (demanda) de diferentes ativos de capital fixo por parte dos setores da economia. Analogamente ao que ocorre na estimação das matrizes insumoproduto (MIP), o cálculo das MAI envolve a estimação de matrizes de absorção de produtos produzidos no país e fora dele. Dessa maneira, a base de dados fornecida pelas MAI permite a análise de impactos do investimento em capital fixo sobre as importações e, também, a análise da dinâmica do processo de penetração e substituição de importações associado à FBCF na economia brasileira (MIGUEZ et al., 2014). Tal estrutura específica da cadeia de absorção da Construção Civil foi utilizada no trabalho em detrimento da UPI, cuja composição considera uma média da alocação na FBCF baseada em todos os setores.

As principais conclusões do trabalho indicam que os investimentos das PPP's, ao propiciar a construção e a ampliação da infraestrutura em Minas Gerais, tendem a aumentar a produção, o emprego e a arrecadação tributária tanto do próprio estado quanto do restante do Brasil. Projeta-se que dos R \$ 15,16 bilhões despendidos nas atividades produtivas, $\mathrm{R} \$ 29,89$ bilhões seriam alcançados em termos de acréscimo na produção, $\mathrm{R} \$ 11,90$ bilhões a mais no PIB e 351 mil postos de trabalhos adicionais. Em termos de arrecadação tributária, a receita aumentaria $\mathrm{R} \$ 1,40$ bilhões considerando os impostos indiretos totais. Além desses impostos gerados pela expansão da atividade produtiva dos setores nas duas regiões, tem-se a parcela dos impostos indiretos arrecadados diretamente pela aplicação dos investimentos das PPP's e também as parcelas relativas aos impostos sobre a produção gerados e arrecadados diretamente. Somando-se todos os impostos, estes representariam cerca de $28 \%$ de todo o montante dos recursos dispendidos pelas PPP's. Assim, o incentivo à implementação de PPP's como forma de manter e de aumentar os investimentos em infraestrutura parece ser positivo inclusive ao orçamento público. Em tempos de crises e de restrições fiscais, as PPP's parecem ser soluções 
alternativas para que projetos não sejam interrompidos e para que outros possam ser viabilizados.

O trabalho também pode evidenciar uma ligação forte entre as economias de Minas Gerais e do restante do Brasil. Mesmo que os projetos tenham sido implementados em Minas Gerais, pode-se observar significativos vazamentos para aquela região. Vale ressaltar que as limitações da metodologia exercem influência sobre as projeções encontradas. Já era esperado que o sistema de equações lineares do modelo juntamente com as hipóteses de retornos constantes de escala e de oferta ilimitada de insumos produzissem projeções positivas sobre a economia de Minas Gerais e do restante do Brasil, tanto em termos macroeconômicos quanto em termos setoriais. Mesmo assim, tal metodologia reconhece as interligações setoriais e regionais na estrutura produtiva. As projeções econômicas, portanto, reproduzem as interdependências setoriais e regionais existentes, sendo observados por meio de efeitos projetados que se distribuem de forma distinta e com intensidade diferenciada.

As repercussões econômicas indicam que os setores mais beneficiados seriam aqueles diretamente ligados com a cadeia de fornecimento de insumos domésticos à Construção Civil, como Máquinas e equipamentos, Metalurgia e Comércio. Constata-se também que a parcela dos efeitos indiretos desses setores é maior nos efeitos totais, o que indica maior dependência comercial. Assim, dentro de um contexto de políticas que visam também estimular as atividades produtivas, as PPP's podem contribuir para aumentar as inversões em bens de capital. Não obstante, a identificação dos setores mais relevantes e projeções sobre a arrecadação podem servir como suporte na confecção dos contratos ou na alocação dos recursos disponibilizados pelo setor público para as PPP's.

Vale destacar que trabalhos empíricos que procuraram avaliar efeitos de PPP's sobre a economia do Brasil são praticamente inexistentes na literatura. Este trabalho contribui para o debate em andamento sobre as PPP's alicerçado na análise dos investimentos gerados em Minas Gerais, proporcionando novas informações aos próximos projetos com a mesma estrutura legal. Para futuros avanços e extensões do estudo, pode-se vislumbrar o uso de um modelo de equilíbrio geral computável de forma a considerar os efeitos complementariedade e de competição inter-regional. Ademais, com essa metodologia, seria possível captar os efeitos competitivos entre as fontes de insumos doméstica e importada. Apesar do trabalho usar os dados mais atualizados disponibilizados pela Secretaria de Estado e Desenvolvimento Econômico de Minas Gerais, trabalhos futuros poderão utilizar dados ainda mais abrangentes, levando em consideração os gastos do setor público nessas parcerias ou de projetos em andamento. 


\section{Referências}

BLANC-BRUDE, F.; GOLDSMITH, H.; VÄLILÄ, T. A comparison of construction contract prices for traditionally procured roads and public-private partnerships. Review of Industrial Organization, v. 35, n. 1-2, 2009.

DOI: https://doi.org/10.1007/s11151-009-9224-1

BRASIL, "Lei no 11.079, de 30 de dezembro de 2004. Institui normas gerais para licitação e contratação de parceria público-privada no âmbito da administração pública." Diário Ofícial da União, 2004.

BRITO, B. M. B. DE; SILVEIRA, A. H. P. Parceria público-privada: compreendendo o modelo brasileiro. Revista do Serviço Público, v. 56, n. 1, p. 7-21, 2005.

DOI: https://doi.org/10.21874/rsp.v56i1.214

BRINKERHOFF, D. W.; BRINKERHOFF, J. M. Public-private partnerships: Perspectives on purposes, publicness, and good governance. Public Administration and Development, v. 31, n. 1, p. 2-14, 2011.

DOI: https://doi.org/10.1002/pad.584

CARDOSO, D. F.; TEIXEIRA, E. C.; GURGEL, A. C.; CASTRO, E. R. Intervenção governamental, crescimento e bem-estar: efeitos da política de equalização das taxas de juros do crédito rural nas regiões brasileiras, Revista Nova Economia. v. 24, n. 2, p. 363388, 2014. DOI: https://doi.org/10.1590/0103-6351/1281

DOMINGUES, E. P; CARVALHO, T. S. Análise dos impactos econômicos dos desembolsos do BDMG nos anos 2005, 2009 e 2010 em Minas Gerais. Cadernos BDMG, v. 21, p. 7-54, 2012.

DOMINGUES, E. P; MAGALHÃES, A. S.; FARIA, W. R. Infraestrutura, crescimento e desigualdade regional: uma projeção dos impactos dos investimentos do Programa de Aceleração do Crescimento (PAC) em Minas Gerais. Pesquisa e Planejamento Econômico, Rio de Janeiro, v. 39, n. 1, p. 121-158, 2009.

FERNANDEZ, R. N. et al. Impacto dos determinantes das parcerias público privadas em economias emergentes. Planejamento e Políticas Públicas, n. 44, 2015.

FITZGERALD, P. Review of Partnerships Victoria Provided

Infrastructure. Melbourne, Australia: Growth Solutions Group, 2004.

FREIBERG, A. The Tools of Regulation. Leichhardt, Australia: Federation Press, 2010.

FRISCHTAK, C. R. O investimento em infraestrutura no Brasil: histórico recente e perspectivas. Pesquisa e Planejamento Econômico, v. 38, n. 2, p. 307-348, 2008.

FUNDAÇÃO JOÃO PINHEIRO (FJP). Mensuração do Impacto Econômico, Social e Ambiental do BDMG. Belo Horizonte: FJP, 2010. (Termo de Cooperação Técnica TC2606/2010 - BDMG e a Fundação João Pinheiro - FJP). 
GUILHOTO, J.J.M., C.R. AZZONI, S.M. ICHIHARA, D.K. KADOTA, E.A. HADDAD. Matriz de Insumo-Produto do Nordeste e Estados: Metodologia e Resultados. Fortaleza: Banco do Nordeste do Brasil. ISBN: 978.85.7791.110.3, 2010.

GUILHOTO, J.J.M., SESSO FILHO, U.A. "Estimação da Matriz Insumo-Produto a Partir de Dados Preliminares das Contas Nacionais". Economia Aplicada, v. 9., n. 2. p. 277-299, 2005. DOI: https://doi.org/10.5897/JAERD12.088

GUILHOTO, J.J.M., SESSO FILHO, U.A. Estimação da Matriz Insumo-Produto Utilizando Dados Preliminares das Contas Nacionais: Aplicação e Análise de Indicadores Econômicos para o Brasil em 2005. Economia \& Tecnologia. UFPR/TECPAR, v. 23, 2010. DOI: https://doi.org/10.5380/ret.v6i4.26912

HODGE, G. A.; GREVE, C. On Public-Private Partnership Performance: A Contemporary Review. Public Works Management \& Policy, v. 22, n. 1, p. 55-78, 2017. DOI: https://doi.org/10.1177/1087724X16657830

INSTITUTO BRASILEIRO DE GEOGRAFIA E ESTATÍSTICA (IBGE). Produto interno bruto dos Municípios. Disponível em: <http://www.sidra.ibge.gov.br >. Acesso em 16 jul. 2016.

JUPE, R. New labour, public-private partnerships and rail transport policy. Economic Affairs, 29, 20-25, 2009.

DOI: https://doi.org/10.1111/j.1468-0270.2009.01862.x

LEITE, A. P. V.; PEREIRA, R. M. Matriz insumo-produto da economia baiana: uma análise estrutural e subsídios às políticas de planejamento. Revista Desenbahia, v. 7, n. 13, p. 99-134, 2010.

MELVILLE, D. Public-Private Partnerships in Developing Countries: Shifting Focus to Domestic-Foreign Partnerships. Review of Market Integration, v. 8, n. 3, p. 152-169, 2016. DOI: https://doi.org/10.1177/0974929217714673

MESQUITA, A. M.; MARTINS, R. S. Desafios logísticos às redes de negócios no Brasil: o que podem as parcerias público-privadas (PPPs)? Revista de Administração Pública, v. 42, n. 4, p. 735-763, 2008. DOI: https://doi.org/10.1590/s0034-76122008000400006

MIGUEZ, T.; FREITAS, F. N. P.; SQUEFF, G. C.; VASCONCELOS, L. F.; MOREIRA, T. M. Uma Proposta Metodológica para a Estimação da Matriz de Absorção de Investimentos para o Período 2000-2009. Brasília: Ipea, 2014.

MILLER, R.E; BLAIR, P.D. Input-output analysis: foundations and extensions. Englewood Cliffs: Prentice-Hall, 2009.

MINAS GERAIS, "Lei no 14.868 , de 16 de dezembro de 2003. Dispõe sobre o Programa Estadual de Parcerias Público-Privadas." Diário Oficial de Minas Gerais, Belo Horizonte, 2003. 
MINAS GERAIS, Governador anuncia contingenciamento de $\mathbf{R} \mathbf{2}$ bilhões em Minas Gerais para enfrentar a crise. Belo Horizonte, 2015. Disponível em <http://www.agenciaminas.mg.gov.br/noticia/governador-anuncia-contingenciamento-der-2-bilhoes-em-minas-gerais-para-enfrentar-a-crise>. Acesso em: 21 jul. 2016.

MINAS GERAIS, Unidade Central De PPP. Belo Horizonte, 2015. Disponível em <http://www.ppp.mg.gov.br/>. Acesso em: 21 jul. 2016.

MOORE, M. Creating public value. Cambridge, MA: Harvard University Press, 1995.

PEREIRA, R. A. C.; FERREIRA, P. C. Efeitos de Crescimento e Bem-estar da Lei de Parceria Público-Privada no Brasil. Revista Brasileira de Economia, v. 62, n. 2, p. 207 219, 2008. DOI: https://doi.org/10.1590/s0034-71402008000200005

ROEHRICH, J. K.; LEWIS, M. A.; GEORGE, G. Are public-private partnerships a healthy option? A systematic literature review. Social Science \& Medicine, v. 113, p. 110-119, 2014. DOI: https://doi.org/10.1016/j.socscimed.2014.03.037

VIEIRA, F. V.; VERÍSSIMO, M. P. Crescimento econômico em economias emergentes selecionadas: Brasil, Rússia, Índia, China (BRIC) e África do Sul. Economia e Sociedade, v. 18, n. 3, p. 513-546, 2009.

DOI: https://doi.org/10.1590/s0104-06182009000300004

VINING, A.; BOARDMAN, A. Public-private partnerships: Eight rules for governments. Public Works Management \& Policy, v. 13, p. 149-161, 2008.

DOI: https://doi.org/10.1177/1087724X08323843 